\title{
Avaliação de impactos e danos ambientais em zonas costeiras do Brasil - Angra dos Reis e Paraty
}

\author{
Bianca Alves Lima Ribeirol'; Nicole Martins Wolff², Elenice Rachid da Silva'; \\ Josimar Ribeiro de Almeida²
}

$\triangle \underline{\text { bianca.ribeiro@poli.ufri.br }}$

\author{
1. Universidade Federal do Rio de Janeiro, Rio de Janeiro, Brasil. 2. Universidade do Estado do Rio de \\ Janeiro, Rio de Janeiro, Brasil
}

Histórico do Artigo:

Recebido em: 14 de agosto de 2018 Aceito em: 25 de fevereiro de 2018

Publicado em: 30 de abril de 2019

Resumo: 0 estudo visa identificar os impactos e danos ambientais e as ações desenvolvidas para a melhoria da qualidade de vida e preservação da biodiversidade das zonas costeiras dos municípios de Angra dos Reis e Paraty, de acordo com a metodologia do modelo Pressão-Estado-Impacto-Resposta (PEIR). As informações sobre o estado do ambiente têm grande importância prática e teórica, visto que a partir delas é possível elaborar um planejamento para minimizar as pressões e impactos sobre o meio ambiente e potencializar as respostas em favor da preservação da biodiversidade e promoção da melhoria da qualidade de vida e bem-estar da população. Na primeira etapa, os dados foram coletados através de pesquisa bibliográfica e organizados em infográficos e tabelas. Na segunda etapa, os resultados foram analisados e discutidos sob a perspectiva do modelo PEIR. Foi observado que os municípios em estudo necessitam de melhorias na infraestrutura urbana básica, o que influencia diretamente na qualidade de vida e saúde da população. Em contrapartida, há iniciativas para a conservação da biodiversidade, como a manutenção de Unidades de Conservação e adesão do município de Paraty ao Passaporte Verde.

Palavras-chave: Gestão ambiental, Preservação ambiental, Modelo Pressão-Estado-Impacto-Resposta.

\section{Environmental impact assessment and damage in coastal areas of Brazil - Angra dos Reis and Paraty}

\begin{abstract}
The research aims to identify the environmental impacts and damages and actions developed to improve the quality of life and preservation of the biodiversity of the coastal zones of the municipalities of Angra dos Reis and Paraty, according to the methodology of the Pressure-State-Impact-Response (PEIR) Model. The information on the state of the environment is of great practical and theoretical importance, since from these it is possible to elaborate a planning to minimize the pressures and impacts on the environment and to potentiate the responses in favor of the preservation of the biodiversity and promotion of the quality improvement life and well-being of the population. In the first stage, the data were collected through bibliographic research and organized into infographics and tables. In the second step, the results were analyzed and discussed from the perspective of the PEIR model. It was observed that the municipalities under study need improvements in basic urban infrastructure, which directly influences the quality of life and health of the population. On the other hand, there are initiatives for the conservation of biodiversity, such as the maintenance of Conservation Units and the adhesion of the municipality of Paraty to the Green Passport.
\end{abstract}

Keywords: Environmental management, Environmental preservation, Pressure-State-Impact-Response (PEIR) Model. 


\section{Evaluación de impactos y daños ambientales en zonas costeras de Brasil - Angra dos Reis y Paraty}

Resumen: La investigación científica tiene por objeto identificar los impactos y daños ambientales y las acciones desarrolladas para mejorar la calidad de vida y la preservación de la biodiversidad de las zonas costeras de los municipios de Angra dos Reis y Paraty, de acuerdo con la metodología del Modelo de Presión-Estado-ImpactoRespuesta (PEIR). Las informaciones sobre el estado del medio ambiente son de gran importancia práctica y teórica, pues a partir de ellas es posible elaborar una planificación para minimizar las presiones e impactos sobre el medio ambiente y potenciar las respuestas en pro de la preservación de la biodiversidad y promoción. de la mejora de la calidad de vida y el bienestar de la población. En la primera etapa, los datos fueron recolectados por medio de investigación bibliográfica y organizados en infografías y tablas. En la segunda etapa, los resultados fueron analizados bajo la perspectiva del modelo PEIR. Se observó que los municipios estudiados aún carecen de mejoras en la infraestructura urbana básica, lo que afecta directamente la calidad de vida y la salud de la población. Por otro lado, existen iniciativas para la conservación de la biodiversidad, como el mantenimiento de Unidades de Conservación y la adhesión del municipio de Paraty al Pasaporte Verde.

Palabras clave: Gestión ambiental, Preservación del medio ambiente, Presión-Estado-Impacto-Respuesta (PEIR).

\section{INTRODUÇÃO0}

A sociedade moderna enfrenta como um dos seus grandes desafios a complexa responsabilidade de conciliar o desenvolvimento econômico e a sustentabilidade socioambiental (RIBEIR0; BARCELLOS, 2013; MEIER et al., 2014; SANTOS et al., 2015), ou seja, o equilíbrio entre o crescimento econômico, a preservação ambiental e a justiça social (DIAS, 2011). 0 litoral fluminense destaca-se pela diversidade de ecossistemas de elevada relevância ecológica, como: florestas, restingas, manguezais (INEA, 2014), os quais têm sofrido acentuados processos de degradação ambiental devido a interferências negativas de origem antrópica, como: poluição do ar, solo e recursos hídricos, ocupação desordenada em áreas ambientalmente vulneráveis, extração exacerbada de recursos naturais, entre outros.

Para compreender a dinâmica dos ecossistemas, é necessário observar as funções ecossistêmicas, as quais podem ser definidas como as relações efetivas entre os elementos estruturais de um ecossistema, inclusive a transferência de energia, ciclagem de nutrientes, regulação de gás, regulação climática e do ciclo da água (DALY; FARLEY, 2004). Na maior parte dos casos, segundo Andrade e Romeiro (2009), uma determinada função ecossistêmica gera um serviço ecossistêmico quando os processos naturais subjacentes provocam benefícios direta ou indiretamente apropriáveis pelo ser humano. Assim, os autores definem que serviços ecossistêmicos são produtos físicos e não físicos produzidos pela natureza independentemente do seu relacionamento com a espécie humana. 
Avaliação de impactos e danos ambientais em zonas costeiras do Brasil - Angra dos Reis e Paraty

Com 0 intuito de promover uma gestão ambiental mais eficiente, existem diversas metodologias de análise ambiental, dentre as quais, considerando as aplicações e práticas mais difundidas prevaleceu, segundo Ariza e Araújo Neto (2010), o modelo Pressão-EstadoImpacto-Resposta (PEIR), desenvolvido pela a Organization for Economic Co-operation and Development (OECD, 1993) para o estudo de indicadores ambientais e complementado pelo PNUMA em 2007. Os autores complementam ainda que essa metodologia é capaz de proporcionar um meio para analisar problemas ambientais sem descartar o fato de que 0 ambiente existe como um sistema de múltiplas interações, inclusive favorecendo compreensão das interseções culturais, históricas, tecnológicas e políticas existentes entre o ser humano e o meio ambiente.

Portanto, considerando que o processo de investigação do ambiente urbano é essencial para a promoção da gestão para o desenvolvimento sustentável (CRESP0; LAROVERE, 2002), este estudo tem como objetivo, identificar os impactos e danos ambientais e as ações desenvolvidas para a melhoria da qualidade de vida e preservação da biodiversidade das zonas costeiras dos municípios de Angra dos Reis e Paraty, a fim de avaliar o conjunto de informações publicamente disponíveis relativas ao modo de uso atual dos recursos naturais locais e seu desdobramento potencialmente impactante para o meio ambiente e sociedade.

\section{MATERIAL E MÉTODOS}

\section{- $\quad$ Área de estudo (abrangência geográfica)}

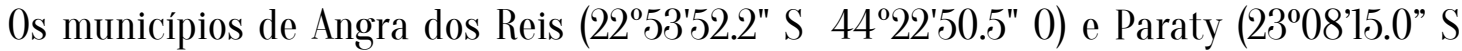
$44^{\circ} 44^{\prime} 34.2^{\prime \prime}$ 0) estão localizados no estado do Rio de Janeiro e compõem uma extensa zona costeira de $350 \mathrm{~km}$ de litoral que forma a baia da Ilha Grande juntamente com o litoral de Mangaratiba (INEA, 2015), conforme apresenta a figura 1. As unidades de conservação correspondem a quase $72 \%$ da área total (terrestre e marinha) dos municípios em estudo. Essas áreas abrigam formações florestais de relevância ambiental, como: restinga, manguezais, ilhas costeiras, arrecifes e costões rochosos. 


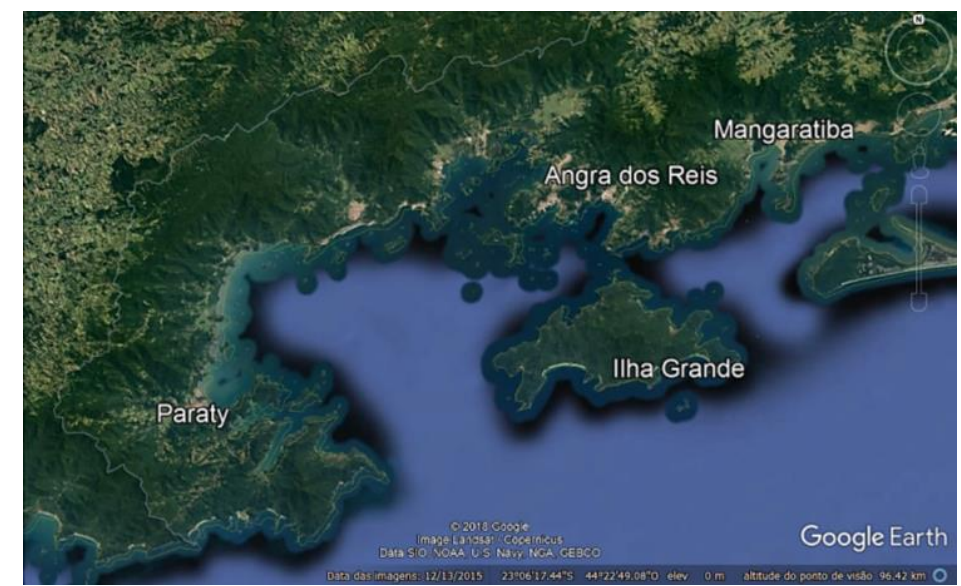

Figura 1: Área de estudo: municípios de Angra dos Reis e Paraty, RJ.

Fonte: Adaptado de Google Earth.

As principais atividades econômicas da região são a pesca, as atividades portuárias, a exploração de óleo e gás offshore, as usinas termonucleares (Angra 1 e Angra 2), construção civil, turismo e agropecuária. Por conta do lançamento de efluentes industriais e domésticos nos corpos hídricos dos municípios, a composição da água tem sido alterada principalmente pelo acúmulo em grandes quantidades de substâncias como nitrogênio e fósforo, além de outras substâncias tóxicas. Essas condições ambientais podem resultar na morte de organismos e propagação de doenças, além de outros impactos (INEA, 2015).

\section{- Descrição metodológica}

Com 0 intuito de tornar a gestão ambiental mais eficiente, existem diversas metodologias de análise ambiental. A Organização para Cooperação e Desenvolvimento Econômico (OCDE) tem se dedicado na tarefa de elaborar indicadores que exprimam a situação ambiental atual e o progresso visando à sustentabilidade. Levando em consideração as aplicações e práticas mais difundidas, a metodologia PEIR (Pressão-Estado-Impacto-Resposta) prevaleceu e permite analisar o ambiente como um sistema organizado sob diferentes dimensões e interações (ARIZA, NET0, 2010). Neste trabalho, a metodologia PEIR foi empregada a fim de reconhecer as potencialidade dos recursos naturais disponíveis e as consequências decorrentes de seu uso.

Os elementos constituintes da matriz PEIR são compreendidos como: "pressão", que se refere às atividades humanas que pressionam o meio ambiente, sensibilizando seus recursos naturais, ou seja, modificando seu "estado", que é composto pelo conjunto das suas condições ambientais. As consequências da alteração do "estado" resultam nos "impactos" e a "resposta" 
Avaliação de impactos e danos ambientais em zonas costeiras do Brasil - Angra dos Reis e Paraty

consiste nas ações voltadas para a mitigação ou resolução do dano causado. (DUTRA et al., 2018; LIMA; COSTA; RIBEIR0, 2017); KRISTENSEN, 2004; RIBEIRO, BARCELLOS, R0QUE, 2013).

Assim, para a caracterização da área em estudo foi realizada pesquisa bibliográfica e documental em bases de dados de diversas instituições com pesquisas. Também foram levantados dados quanto aos ecossistemas que compõem os municípios, dados demográficos, infraestrutura urbana e atividades econômicas desenvolvidas na região.

Posteriormente, realizou-se a sistematização dos dados coletados, com a elaboração de infográficos e tabelas, visando facilitar a compreensão quanto à distribuição dos dados.

\section{RESULTADOS E DISCUSSÃ0}

\section{- $\quad$ Pressão-Estado-Impacto-Resposta: Pressão}

A análise da dinâmica populacional da área em estudo é de fundamental importância para a compreensão da pressão antrópica exercida no meio ambiente, quanto maior a população, maior será o seu consumo e consequentemente, maior será a extração de recursos naturais (MALTHUS, 1950; MATOS, 2012; VARGAS, 1998; MARTINE, 2007).

Entre 2000 e 2010, de acordo com dados compilados por Atlas do Desenvolvimento Humano no Brasil, a população de Angra dos Reis evoluiu a uma taxa média de 3,58\%, destacando-se, segundo TCE (2017), como o $11^{\circ}$ maior crescimento populacional na comparação entre as décadas, enquanto Paraty apresentou crescimento de $27 \%$, o $19^{\circ}$ maior crescimento no estado. Ao observar 0 gráfico 1, é possível perceber um expressivo incremento populacional no município de Angra dos Reis entre a década de 1990 e o ano 2015, e em contrapartida, observase um crescimento mais discreto em Paraty considerando o mesmo intervalo de tempo.

Gráfico 1: População residente nos municípios de Angra dos Reis e Paraty (1991 à 2015).

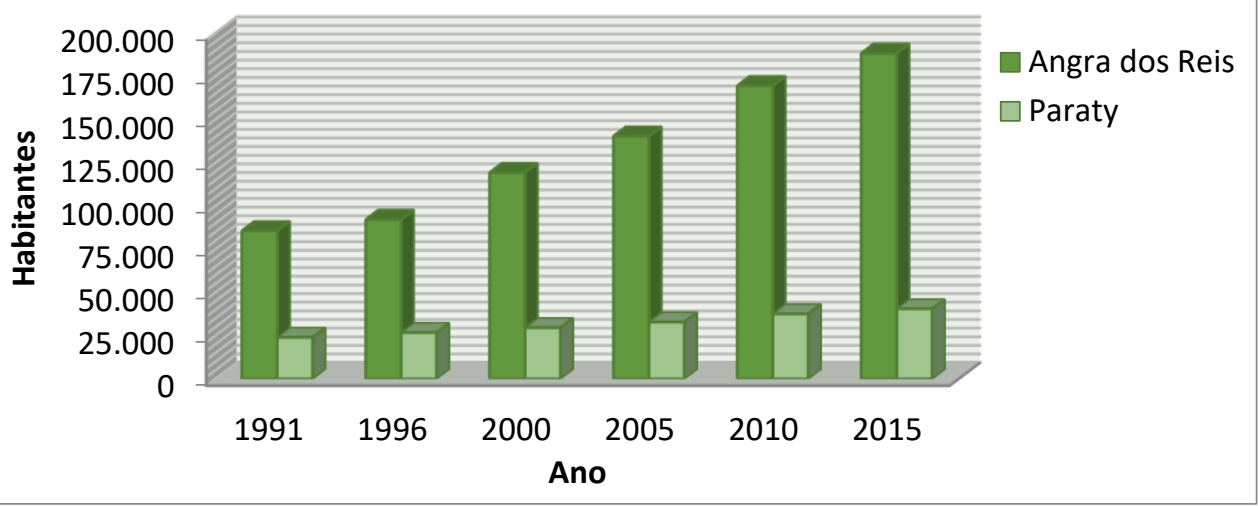

Fonte: IBGE, TCE Estudos Socioeconômicos, PNUD, Ipea e FJP. 
No que se refere à distribuição da população nas zonas territorial urbana e rural, Angra dos Reis permanece com seu perfil urbano de acordo com dados de 1991 a 2010, conforme gráfico 2, mantendo seu contingente populacional urbano sempre acima dos 90\%. Contudo, Paraty somente apresentou um crescimento efetivo na população urbana no ano de 2010, quando houve a ocupação de 73,77\% dos habitantes de Paraty na zona urbana.

Gráfico 2: Percentual de população rural e urbana dos municípios de Angra dos Reis e Paraty (1991, 2000, 2010).

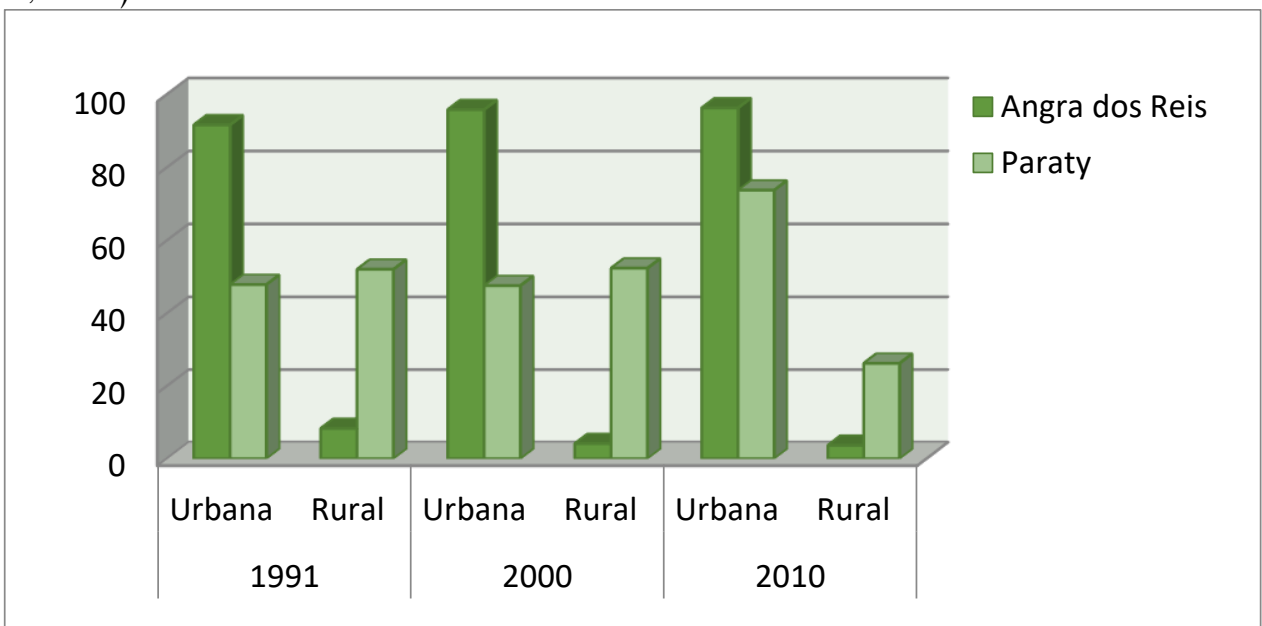

Fonte: IBGE, PNUD, Ipea e FJP

Para fins de análise das variações temporais do crescimento populacional, utiliza-se como parâmetro a taxa de crescimento populacional, que consiste no "percentual de incremento médio anual da população residente em determinado espaço geográfico, no período considerado", conforme IBGE (2010). Desse modo, o valor da taxa refere-se a um período de tempo no intervalo de dois momentos que, em geral, corresponde aos anos dos censos demográficos. A taxa é diretamente influenciada pela dinâmica da natalidade, da mortalidade e das migrações da área em estudo (IBGE, 2010).

Tendo isso em vista, Angra dos Reis teve um aumento da sua taxa de crescimento populacional de 0,22\% quando comparados os períodos de 2000-2010 e 1991-2000, enquanto em Paraty o crescimento foi de apenas $0,05 \%$ Portanto, nota-se uma tendência de que Angra dos Reis permaneça um município mais populoso que Paraty pelos próximos anos.

Segundo definição do IBGE, a densidade demográfica é medida através da relação entre a população e o território, expressa geralmente em habitantes por quilômetro quadrado. Diante disso, pode-se considerar que a medida da densidade demográfica e da taxa de crescimento populacional são duas ferramentas importantes para o estudo prognóstico da pressão antrópica exercida sobre os recursos naturais nas áreas em estudo. Em 2010, segundo 
Avaliação de impactos e danos ambientais em zonas costeiras do Brasil - Angra dos Reis e Paraty

IBGE, a densidade demográfica de Angra dos Reis era de 205,8 hab $/ \mathrm{km}^{2}$, enquanto a de Paraty apresentava 40,36 hab/ $\mathrm{km}^{2}$.

Segundo Matos (2012, p. 456), “população e recursos naturais guardam vínculos associativos decisivos para o entendimento das trajetórias da mortalidade, natalidade e migrações, e isso afeta o crescimento demográfico". Destaca-se que mortalidade, natalidade e migrações são exatamente os fatores que influenciam no cálculo da taxa de crescimento populacional.

Outro componente importante a ser observado consiste no grau de desenvolvimento humano dos municípios em estudo. Segundo a 0NU (2001, p. 9-10), o desenvolvimento humano "é muito mais do que a ascensão ou a queda de rendas nacionais. É criar um ambiente em que os povos podem desenvolver seu potencial pleno e conduzir suas vidas produtivas e criativas de acordo com suas necessidades e interesses”. De 1991 até 2010, ambos os municípios em estudo apresentaram crescimento no seu Índice de Desenvolvimento Humano Municipal (gráfico 3), calculado segundo dados da educação, longevidade (esperança de vida ao nascer) e renda per capita. A partir de 2000, o avanço do IDHM de Angra dos Reis se mostrou mais expressivo, até alcançar o índice de 0,724 enquanto Paraty chegou a 0,693.

Gráfico 3: Índice de Desenvolvimento Humano Municipal de Angra dos Reis e Paraty (1991, 2000, 2010).

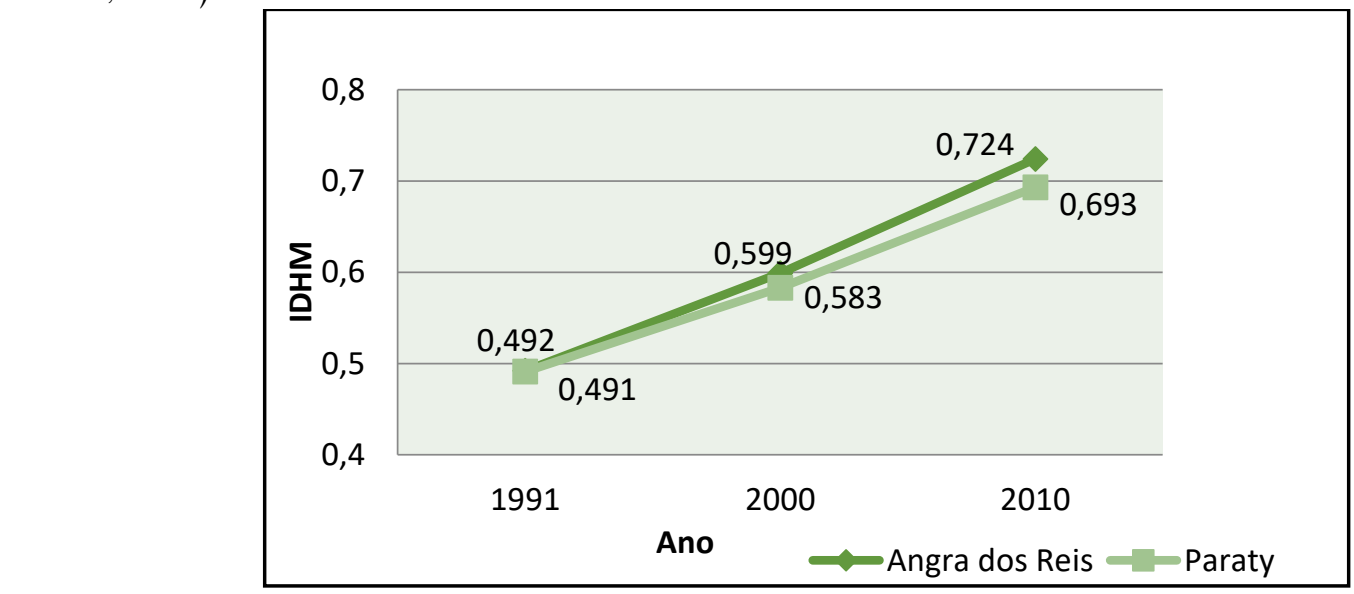

Fonte: PNUD, Ipea e FJP

\section{- $\quad$ Pressão-Estado-Impacto-Resposta: Estado}

A avaliação do estado deve contemplar aspectos qualitativos e quantitativos dos recursos naturais, a fim de relacionar a perspectiva ambiental e a qualidade de vida da população dependente desses recursos (PNUMA, 2008). Além da perspectiva ambiental, neste item também serão apresentados dados referentes às condições de acesso da população dos 
municípios em estudo aos serviços urbanos básicos, pois as condições habitacionais podem favorecer ou minimizar a ocorrência de doenças, o interfere diretamente na qualidade de vida dessas pessoas (RAHMAN; RAHMAN, 1997; VICTORA, 1996).

\section{- $\quad$ Caracterização da biodiversidade da área em estudo}

Com base no Diagnóstico do Setor Costeira da Baía de Ilha Grande (2015), a região da Baía da Ilha Grande, que engloba os municípios de Angra dos Reis e Paraty, está inserida no bioma Mata Atlântica, o qual detém alto grau de biodiversidade. A formação vegetal dominante é a floresta ombrófila densa, fitofisionomia que recobre uma vasta área da região. Na linha de costa, há presença de formação florestal característica de restinga com indivíduos arbóreos e alto grau de similaridade à vegetação ombrófila das terras baixas e submontanas. Há formação de ecossistemas de manguezal distribuídos por extensas áreas como na foz do rio Jurumirim e nas rias ou vales, conforme INEA (2015). A fitofisionomia de manguezal também pode ser observada na foz dos rios Mambucaba, Ariró e Bracuhy; nas Praias do Recife e Porto Marisco, na Ilha do Jorge Grego, e nas localidades de Japuíba e Caiera (SEA; SIDRAP; SEDEIS, 2012).

0 manguezal é representado por ocorrer em locais de transição entre ambientes marinhos e terrestres e por apresentar espécies arbóreas com raízes aéreas (Rhizophora mangle - mangue-bravo ou vermelho, Avicena schaueriana - mangue-seriba ou seriúba - e Laguncularia racemosa- mangue-branco) e gramíneas (Spartina sp), tolerantes à imersão durante as marés cheias. No que se refere à floresta ombrófila densa, consiste em uma estrutura fitofisionômica de estrutura complexa, de aspecto exuberante e úmido com muitas lianas e epífitas, apresentando riqueza de espécies distribuídas em estratos distintos (INEA, 2015).

Na região da Baía da Ilha Grande, há diversas espécies arbóreas características de floresta ombrófila densa, conforme é listado na tabela 1. Há que se destacar que devido ao extrativismo descontrolado da espécie Euterpe edulis (palmito) encontra-se ameaçada de extinção.

Tabela 1: Espécies da flora que ocorrem na Baía da Ilha Grande.

\begin{tabular}{cc}
\hline Nome científico & Nome popular \\
\hline Andira anthelmia & angelim \\
Aspidosperma sp & peroba \\
\hline
\end{tabular}


Avaliação de impactos e danos ambientais em zonas costeiras do Brasil - Angra dos Reis e Paraty

\begin{tabular}{|cc|}
\hline Cabralea canjerana & canjerana \\
Cedrela ocbrata & - \\
\hline Cedrela fissilis & cedro \\
\hline Chorisia speciosa & paineira \\
Clitoria racemosa & sombreiro \\
Cryptocaria moschata & canela-branca \\
Nectandra mollis & canela-preta \\
\hline Hymenaea coubaril & jatobá \\
\hline Joannesia princeps & boleira \\
\hline Pouteria fissilis & guaricica \\
Pouteira lauriflora & guapeva \\
\hline Ocotea divaricata & caneleiras \\
Ocotea pretiosa & canela-sassafrá \\
\hline Piptadenia spp & angico \\
Euterpe edulis & palmito \\
\hline
\end{tabular}

Fonte: INEA (2015).

Além da exuberância da flora, a região conta com uma diversidade de fauna. 0s principais levantamentos faunísticos para a região foram realizados para a confecção dos Planos de Manejo das Unidades de Conservação, principalmente: Parque Nacional da Serra da Bocaina (PNSB), Parque Estadual da Ilha Grande (PEIG) e Área de Proteção Ambiental (APA) de Cairuçu. No PNSB, foram registradas 40 espécies de mamíferos não voadores, incluindo espécies características da Mata Atlântica como o ouriço-cacheiro (Sphiggurus villosus).

Foram observados também mamíferos voadores, roedores, marsupiais e felinos, como: a onça-parda, a jaguatirica, o gato do mato (Leopardus tigrinus) e 0 jaguarundi (Herpailurus yaguarondi). (MMA/ IBAMA, 2001; INEA, 2015). No plano de manejo da APA de Cairuçu (MMA/IBAMA, 2004) são listadas 26 espécies de répteis e 35 de anfíbios, incluindo serpentes, como: jararaca (Bothrops jararaca) e a cobra cipó (Chironius bicarinatus) e também anuros populares como o Bufo sp. (sapo-cururu).

Quanto as aves, foram levantadas 345 espécies na APA de Cairuçu como: 0 tiê-sangue (Ramphocelus bresilius), o trinca-ferro (Saltator similis), o Canário da terra (Sicalis flaveola) e Coleirinhas (Sporophila caerulescens). No levantamento para o PNSB, foram registradas 294 espécies incluindo 130 espécies apontadas como endêmicas da Mata Atlântica e 12 ameaçadas de extinção (INEA, 2015).

Há também uma relevante diversidade ecológica de fitoplâncton, zooplâncton e bentos (fitobentos e zoobentos). Além de peixes, quelônios e mamíferos marinhos. Hetzel e Lodi (1996) consideram que a baía da Ilha Grande concentre uma das maiores diversidades de cetáceos no Brasil. Há registro de 14 espécies das subordens Mysticeti e Odontoceti. Dentre os Misticetos, 
as mais frequentes são as baleias franca-do-sul (Eubalaena australis) e jubarte (Megaptera novaeangliae), ambas com hábitos migratórios bem conhecidos para a Costa Brasileira (INEA, 2015).

\section{Infraestrutura Urbana}

\section{Água encanada}

Estima-se que cerca de 10 \% da carga global de doenças seja devida à má qualidade da água e a deficiências na disposição de excretas e na higiene. (PRÜSSUSTIN et al. 2008). Razzolini (2008) destaca que aumento da expectativa de vida e produtividade econômica, hábitos higiênicos, controle e prevenção de doenças são consequências das condições adequadas de abastecimento de água para a população. Para Lima et al (2017, p. 1077) "a distribuição de água é um condicionante de política pública de saneamento básico, que interfere de maneira significativa na saúde”. Por isso é uma questão de saúde pública e ambiental que a população tenha pleno acesso à água devidamente tratada em seus domicílios.

Entre os municípios em estudo, Angra dos Reis apresenta um abastecimento de água mais amplo que Paraty. Enquanto o percentual da população de Angra dos Reis passou de 88,16\%, em 1991, para 92,49\% em 2010, Paraty apresentou um aumento entre as décadas de 1991 e 2000 (de 81,65\% para 88,89\%), porém na década seguinte, houve um decréscimo para apenas $81,39 \%$.

No que tange o esgotamento sanitário dos municípios em estudo, o Diagnóstico do Setor Costeira da Baía de Ilha Grande (2015), aponta que "o crescimento rápido e desordenado da população (tanto fixa quanto flutuante) da região tem contribuído para a multiplicação de lançamentos clandestinos, tanto diretamente nos corpos hídricos quanto por meio de ligação com a rede de águas pluviais".

0 Serviço Autônomo de Água e Esgoto de Angra dos Reis (SAAE), segundo SNIS (2011) trata o esgoto sanitário de 46,7 \% da população urbana, correspondente a 45\% da população total do município (SNIS, 2011). Todavia, em Paraty, não existe nenhum sistema de coleta e tratamento de esgoto, exceto a Vila Residencial de Mambucaba e o Condomínio Laranjeiras que mantêm sistemas próprios para este fim. 
Avaliação de impactos e danos ambientais em zonas costeiras do Brasil - Angra dos Reis e Paraty

\section{Coleta de lixo}

Todos os resíduos gerados pelo município de Paraty são encaminhados para o Centro de Tratamento de Resíduos (CTR) Costa Verde, um aterro sanitário situado no município de Angra dos Reis, que, por sua vez, também recebe os resíduos sólidos do seu município, conforme consta no Plano Municipal de Gestão Integrada de Resíduos Sólidos (PMGRIS) de Paraty, de 2015.

Como em Paraty não existe uma estação de transferência de resíduos, essa operação é realizada em uma pequena área ambientalmente inadequada para a função e que até 2012 recebia todos os resíduos do município, local denominado Lixão Boa Vista. Os caminhões compactadores descarregam os resíduos de forma indevida no solo e, posteriormente, ocorre a operação de transferência com uma pá carregadeira até os caminhões encarregados de transportar até a área de disposição final, o Aterro de Ariró, situado em Angra dos Reis (UERJ, 2011).

Os resíduos coletados nos municípios são resultado da varrição dos logradouros públicos, coleta de resíduo domiciliar e insular, e outros serviços, como: capina, roçada, poda, serviços especiais e resíduos da construção civil e de saúde, por exemplo. A coleta é realizada através sistema de coleta manual (porta-a-porta) nos logradouros públicos.

Em 2010, de acordo com dados do Atlas de Desenvolvimento Humano, Angra dos Reis a coleta de resíduos alcançou 99,26\% da sua população e Paraty 98,30\%. Desde 1991, é possível verificar que Paraty teve aumento de 81,65\% em 1991 para 98,30\% em 2010 e Angra dos Reis, em 1991, atendia 81,65\%, e em 2010 chegou a 99,26\% da população atendida por esse serviço.

\section{Energia elétrica}

A falta de acesso à energia elétrica favorece a progressão de assimetrias sociais, induzindo a manutenção da pobreza e desacelerando o desenvolvimento econômico com o incentivo indireto no fluxo migratório de trabalhadores para cidades mais desenvolvidas (NADAUD, 2012). Por isso, é necessário estudar a dinâmica de acesso a energia elétrica, a fim de traçar, dentre outros fatores, o perfil de desenvolvimento econômico e social dos municípios em estudo.

Segundo dados do Atlas do Desenvolvimento Humano, nota-se que no município de Angra dos Reis, em 2010, apenas 0,23\% da população não tinha acesso à energia elétrica. Em Paraty, é possível observar que houve um forte incremento no percentual de habitantes com 
acesso à energia elétrica em seus domicílios de 1991 a 2010, com aumento de 74,97\% para $98,02 \%$ da população.

\title{
- Pressão-Estado-Impacto-Resposta: Impacto Socioambiental
}

À medida que a humanidade aumenta sua capacidade de intervir na natureza para satisfação de necessidades crescentes, surgem tensões e conflitos quanto ao uso do território e seus recursos (RIBEIR0; BARCELLOS; ROQUE, 2013), principalmente quando há incompatibilidade entre meio ambiente e desenvolvimento econômico (FONSECA; OLIVEIRA; SOUSA, 2012). Com o avanço da ocupação urbana desordenada há o agravamento de problemas e impactos diversos como o lançamento de efluentes domésticos e industriais e a ocupação de áreas de preservação (INEA, 2015)

\begin{abstract}
"Os impactos antrópicos que incidem sobre a zona costeira são comumente associados a vetores de desenvolvimento em franco processo de expansão, como o turismo, a implantação de parques eólicos e de grandes estruturas industriais, portuárias e logísticas ligadas, sobretudo, à exploração petrolífera offshore. Quaisquer atividades desenvolvidas no ambiente marinho implicam na ocupação de espaços costeiros e continentais, podendo trazer impactos negativos como 0 desenvolvimento urbano descontrolado e o aumento da especulação imobiliária (INEA, 2015)".
\end{abstract}

Em consonância com Acselrad (2004), é possível afirmar que os conflitos ambientais surgem quando há divergência entre o modo de sobrevivência de alguns grupos sociais no território sofre consequências indesejadas resultante das ações de outros grupos sociais.

De um modo geral e no contexto da metodologia PEIR, o impacto pode ser compreendido como as consequências das ações executadas sobre o estado do ambiente em termos do meio ambiente natural, ambiente construído, economia urbana local, qualidade de vida e a saúde humana (ARIZA; ARAUJ0 NET0, 2010). Assim, também é possível admitir que o impacto demonstre as consequências das condições do estado do ambiente sobre a saúde e bem-estar da população (RIBEIR0; BARCELLOS; ROQUE, 2013).

Na APA de Cairuçu, localizada no município de Paraty, existem diversos conflitos ambientais que atingem as comunidades tradicionais (comunidades quilombolas, indígenas e caiçaras) em alguns aspectos. Segundo informações contidas no Plano de Manejo da APA de Cairuçu (2018) são conflitos na área: comunidades indígenas requerendo aumento da área de suas terras, sobreposição de terra indígena com área do PARNA da Bocaina, presença de comunidades caiçaras que não possuem o registro de suas terras. 
Avaliação de impactos e danos ambientais em zonas costeiras do Brasil - Angra dos Reis e Paraty

No município também havia um local inadequado para disposição de resíduos até o ano de 2012, denominado Lixão de Boa Vista, localizado a cerca de $5 \mathrm{~km}$ da região central da cidade. Contudo os resíduos não foram retirados do local e há uma estimativa de que 80 mil toneladas de resíduos e rejeitos estejam alocadas de forma ambientalmente inadequada no local, conforme estimativa do Plano Municipal de Saneamento Básico de Paraty.

A permanência desses resíduos e rejeitos sem tratamento em uma área sem impermeabilização do solo, captação de gás e lixiviados e a céu aberto oferecem riscos iminentes de contaminação do solo, proliferação de vetores de doenças, emissões atmosféricas prejudiciais à saúde humana e ambiental, dentre diversos outros impactos. É necessário ressaltar também a ininterrupta acumulação de biogás no solo, pois pode torná-lo instável e favorecer deslizamentos de taludes. Atualmente uma porção dessa localidade é utilizada como estação de transferência de resíduos, que posteriormente são encaminhados para o Aterro de Ariró, em Angra dos Reis.

Na área da Zona Costeira da Baía da Ilha Grande, que engloba os municípios de Angra dos Reis, Paraty e Mangaratiba, há a ocorrência de diferentes conflitos ambientais, como é apresentado no Diagnóstico do Setor Costeiro da Baía da Ilha Grande (2015). Há problemas quanto às construções irregulares na zona costeiras, como: ocupação desordenada e irregular em áreas costeiras, aterramento do espelho d’água, supressão de vegetação, conflitos fundiários.

0 turismo também tem gerado divergências no que tange a segurança da população local frente aos turistas, excesso de concentração de turistas em pontos específicos, atividades industriais e excesso de visitantes que sobrecarregam a capacidade de suporte do ambiente.

A pesca industrial têm diminuído os recursos pesqueiros, o que afeta diretamente os pescadores artesanais que dependem da pesca para sobreviver, além da pesca predatória que resulta em degradação ambiental e da poluição industrial (lançamento de óleo e substâncias químicas) causada pelos grandes barcos de pesca. Cabe ressaltar a ocorrência de pesca de arrasto, que devasta 0 ambiente prejudicando ainda mais o pescador artesanal.

Existem comunidades tradicionais na região que vivem sem serviços básicos e sem acesso a emprego e, consequentemente, não possuem renda própria. Em contrapartida, há praias sendo privatizadas, resultando na expulsão da população nativa das áreas. Esse cenário eleva o custo de vida e muitas vezes, culmina em ocupação irregular de orlas e encostas, além de monopolizar os recursos naturais ali presentes. 
Outro conflito muito presente está no contexto do transporte marítimo e da produção na camada de Pré-Sal. Ambos acarretam possíveis vazamentos de hidrocarbonetos na água. Destaca-se também para a troca da água de lastro das embarcações que pode acarretar a introdução de espécies exóticas ao ambiente, como é o caso do coral-sol (Tubastraea sp). A grande circulação de embarcações também afugenta peixes, o que dificulta a pesca, sem contar que aumenta as chances de acidentes entre banhistas e lanchas, por exemplo. A instalação da Central Nuclear em Angra dos Reis resultou em um conflito paisagístico para a região.

\section{- $\quad$ Pressão-Estado-Impacto-Resposta: Resposta}

No âmbito da metodologia PEIR, compreende-se por resposta as ações "coletivas ou individuais que atenuam ou previnem impactos ambientais negativos, corrigem os danos causados ao meio ambiente, preservam os recursos naturais ou contribuem para a melhoria da qualidade de vida da população local” (PNUMA e Consórcio Parceria 21, 2004).

Em 2015, foi publicado pelo Instituto Estadual do Ambiente do Rio de Janeiro (INEA) o Diagnóstico do Setor Costeiro da Baia da Ilha Grande onde é apresentado o Zoneamento Ecológico-Econômico Costeiro (ZEEC). Este documento caracteriza-se como um instrumento da gestão ambiental especialmente para as zonas costeiras, e tem a finalidade de promover uma compatibilidade com os diferentes tipos de uso do espaço, e também a regulação das atividades que ocorrem nas regiões costeiras. 0u seja, é uma iniciativa relevante no contexto do planejamento para a preservação dos recursos naturais da região.

A cidade de Paraty foi escolhida como município pioneiro da Campanha Internacional Passaporte Verde, desenvolvido no âmbito da Força Tarefa Internacional para 0 Desenvolvimento Sustentável, composta por 20 países sob liderança do governo francês. 0s Ministérios do Meio Ambiente, do Turismo e o PNUMA serão os responsáveis por coordenar esse projeto em solo nacional, cuja campanha será oficialmente lançada em dezembro de 2018.

0 objetivo consiste em estimular o turista a assumir uma postura sustentável diante do consumo e formas de interação com o ambiente a fim de reduzir os impactos negativos de suas ações e escolhas sobre o local visitado. Em contrapartida o município deve criar condições estratégicas e sustentáveis que sejam atrativas ao público e, para isso, segundo Ministério do Meio Ambiente, será necessário elaborar um diagnóstico da atividade turística local e melhorar a infraestrutura, como o saneamento, por exemplo. 
Avaliação de impactos e danos ambientais em zonas costeiras do Brasil - Angra dos Reis e Paraty

No Parque Estadual da Ilha Grande, há a iniciativa BIG 2050, resultado do Projeto de Gestão Integrada do Ecossistema da Baía da Ilha Grande (Projeto BIG), uma cooperação entre a Secretaria de Estado do Ambiente (SEA) e a Organização das Nações Unidas para Alimentação e Agricultura (FA0), cujo objetivo é planejar e implantar um modelo de gestão ambiental eficiente na região, promovendo a conservação e 0 uso sustentável da baía e de sua biodiversidade, considerada de importância global (BRASÍLIA, 2017).

A criação de Unidades de Conservação (UC) também é uma forma de preservar o meio ambiente e simultaneamente colaborar com a qualidade de vida da população, pois mantêm áreas verdes com possibilidade de visitação, melhora a qualidade do ar, dentre outras vantagens. As UC's além de desempenharem sua função principal de preservar os recursos naturais da área também contribuem de forma eficiente para 0 enfrentamento de desafios globais, como a mudança climática (MEDEIROS, 2011), ou seja, oferecem benefícios tanto a nível local quanto global.

Nos municípios em estudo, há a presença das seguintes Unidades de Conservação: Área de Proteção Ambiental de Cairuçu, Estação Ecológica de Tamoios (bioma marinho costeiro), Parque Estadual da Ilha Grande (PEIG) e Parque Nacional da Serra da Bocaina

\section{CONCLUSÃO}

De acordo com os dados coletados para a área de estudo analisada, é possível afirmar que os municípios de Angra dos Reis e Paraty apresentam deficiências quanto à infraestrutura urbana municipal, no que tange ao acesso à água potável, saneamento básico e iluminação elétrica residencial e coleta, destinação e disposição final de resíduos de forma ambientalmente adequada. Por isso, mostra-se necessário que sejam realizadas melhorias nesses serviços.

Além disso, foram identificadas ações governamentais e sociais que visam a gestão ambiental e, consequente, preservação ambiental. Contudo, essas iniciativas ainda são escassas frente ao volume de pressões ambientais incidentes nas áreas de estudo.

Espera-se que os dados apresentados neste trabalho possam auxiliar os líderes governamentais e tomadores de decisão no que tange a observação de oportunidades de melhoria na infraestrutura básica e a necessidade de ampliar as ações a favor do desenvolvimento social a ambiental que já estão sendo executadas e são bem-sucedidas. 


\section{REFERÊNCIAS BIBLIOGRÁFICAS}

ACSELRAD, H. (org.). Conflitos Ambientais no Brasil. Rio de Janeiro: Relume Dumará; Fundação Heinrich Böll, 2004. $243 \mathrm{p}$.

ALMEIDA, J. R. et al. Política e Planejamento Ambiental. 3 ed. Rio de Janeiro: Thex, 2008. 457 p.

ANGRA DOS REIS (Prefeitura). Secretaria de Desenvolvimento Urbano e Sustentabilidade. Plano Municipal de Gestão Integrada de Resíduos Sólidos de Angra dos Reis. Angra dos Reis. 2017. 258 p.

ARIZA, C. G.; ARAUJO NETO, M. D. de. Contribuições da geografia para avaliação de impactos ambientais em áreas urbanas, com o emprego da metodologia Pressão - Estado Impacto - Resposta (P.E.I.R.). Caminhos de Geografia, v. 11, n. 35, p.128-139, Uberlândia, 2010.

ATLAS DE DESENVOLVIMENTO HUMANO NO BRASIL. Angra dos Reis. Disponível em: $\langle$ http://atlasbrasil.org.br/2013/pt/perfil_m/angra-dos-reis_rj > Acesso em 20 de junho de 2018. de 2018.

Paraty. Disponível em: <http://www.atlasbrasil.org.br/2013/pt/perfil_m/paraty_rj > Acesso em 20 de junho

BENCHIMOL, M. F. Gestão de Unidades de Conservação Marinhas: Um Estudo de Caso da Área de Proteção Ambiental da Baía de Paraty - RJ. 2007. 126 f. Dissertação (Mestrado em Geografia) - Instituto de Geociências, Universidade Federal do Rio de Janeiro, Rio de Janeiro, 2007. Disponível em: 〈http://objdig.ufrj.br/16/teses/681l38.pdf >. Acesso em 21 de junho de 2018.

BERLINGUER, G. Globalização e saúde global. Estudos Avançados, v. 13, n. 35, p.21-38, São Paulo, 1999. Disponível em $\langle$ http://www.revistas.usp.br/eav/article/view/9454 $>$. Acesso em 20 de julho de 2018.

DALY, H. E., FARLEY, J. Ecological Economics: Principles and Applications. Island Press, Washington, DC. 2004. 484 p. Disponível em $<$ https://indomarine.webs.com/documents/Ecological_Economics_Principles_And_Applications.pdf $>$. Acesso em 20 de julho de 2018 .

DE GR00T, R. S.; WILSON, M. A.; BOUMANS, R. M. J. A typology for the classification, description and valuation of ecosystem functions, goods and services. Ecological Economics. v. 41, p. 393-408, 2002. Disponível em http://ww2.oikos.unam.mx/CIEco/comunidades/files/De\%20Groot,\%202002_VALUATION\%200F\%20ECOSYSTEM\%2 0FUNCTIONS,\%20G00DS\%20AND\%20SERVICES.pdf. Acesso em 22 julho de 2018.

DUTRA, Vítor Abner Borges et al. Saneamento em Áreas Urbanas na Amazônia: Aplicação do Sistema de Indicadores PEIR. Revista Gestão \& Sustentabilidade Ambiental, v. 7, n. 2, p.652-671, Santa Catarina, 2018. Disponível em 〈http://www.portaldeperiodicos.unisul.br/index.php/gestao_ambiental/article/view/6234 >.Acesso em 23 de julho de 2018.

FONSECA, B. C.; OLIVEIRA, M. L. R.; SOUSA, D. R. N. Conflitos Ambientais: Atores, Causas e Desdobramentos na Zona da Mata Mineira. Caminhos de Geografia. v. 13, n. 42, p. 283-299, Uberlândia, 2012. Disponível em $\langle$ http://www.seer.ufu.br/index.php/caminhosdegeografia/article/viewFile/16743/9784〉. Acesso em 16 de julho de 2018.

HETZEL, B.; LODI, L. Baleias, Botos e Golfinhos da Baía da Ilha Grande: Resposta e Indicadores Ambientais. Manati, 1996. 49 p. Disponível em 〈http://www.fao.org/ag/againfo/programmes/pt/lead/toolbox/Refer/EnvIndi.htm〉. Acesso em 10 de maio de 2013.

IBGE CIDADES. Angra dos Reis. Disponível em <https://cidades.ibge.gov.br/brasil/rj/angra-dos-reis $>$ Acesso em 02 de junho de 2018.

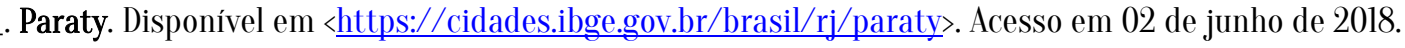

INEA. Secretaria do Meio Ambiente. Diagnóstico do Setor Costeiro da Baía da Ilha Grande: Subsídios à Elaboração do Zoneamento Ecológico-Econômico Costeiro. Rio de Janeiro. Inea, 2015. 242 p. Disponível em 
Avaliação de impactos e danos ambientais em zonas costeiras do Brasil - Angra dos Reis e Paraty

〈http://www.inea.rj.gov.br/cs/groups/public/documents/document/zwew/mdcz/ edisp/inea0073532.pdf〉. Acesso em 20 de maio de 2018.

InSTITUT0 BRASILEIR0 DE ge0grafia E eSTATíSTICA. Sinopse do Censo Demográfico 2010. Disponível em $<$ https://censo2010.ibge.gov.br/sinopse/index.php?dados=216uf=33〉. Acesso em 10 de junho de 2018.

KRISTENSEN, P. The DPSIR framework. In: Workshop on a Comprehensive/ Detailed Assessment of the Vulnerability of Water Resources to Environmental Change in Africa Using River Basin Approach, p. 1-10, Kenya, 2004. UNEP Headquarters, Disponível em < https://wwz.ifremer.fr/dce/content/download/69291/913220/file/DPSIR.pdf >. Acesso em 15 de julho de 2018.

LIMA, V. M.; COSTA, S. M. F.; RIBEIR0, H. Uma Contribuição da Metodologia PEIR para o Estudo de uma Pequena Cidade na Amazônia: Ponta de Pedras, Pará. Saúde Sociedade São Paulo, v. 26, n. 4, p. 1071-1086, São Paulo, 2017. Disponivel em 〈http://www.scielo.br/pdf/sausoc/v26n4/1984-0470-sausoc-26-04-1071.pdf〉. Acesso em 06 de janeiro de 2019.

MALTHUS, T. R. Ensaio sobre a População. Ed. Abril Cultural. São Paulo, 1983.

MAT0S, R. População, Recursos Naturais e Poder Territorializado: uma Perspectiva Teórica Supratemporal. Revista Brasileira de Estudos de População, v. 29, n. 2, p. 451-476, Rio de Janeiro, 2012.

MEDEIROS, $R$ et al. Contribuição das unidades de conservação brasileiras para a economia nacional. Sumário Executivo. Brasília: UNEP-WCMC, 2011. 44 p.

MEIER, M. A. et al. Sociedade Moderna Industrial e a Educação Ambiental: Desafios Industriais - Ambientais do COREDE Vale do Rio dos Sinos. Geographia 0pportuno Tempore, v. 1, n. 2, p. 348-363, Londrina, 2014. Disponível em

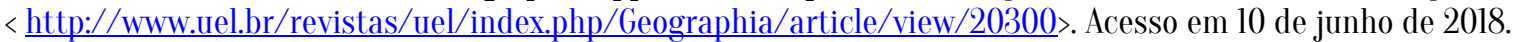

MINISTÉRI0 D0 MEI0 AMBIENTE. Ministério Apoia Iniciativa BIG 2050. Brasília. 2017. Disponível em 〈http://www.mma.gov.br/index.php/comunicacao/agencia-informma?view=blogofid=2563〉. Acesso em 10 de julho de 2018.

MINISTÉRIO DO MEI0 AMBIENTE. Paraty é a Primeira Cidade do Mundo a Implementar o Passaporte Verde. Brasília. Disponível em <http://www.mma.gov.br/informma/item/5105-paraty-e-a-primeira-cidade-do-mundo-aimplementar-0-passaporte-verde>. Acesso em 17 de junho de 2018.

NADAUD, G. C. A. Acesso à Energia Elétrica de Populações Urbanas de Baixa Renda: 0 Caso das Favelas do Rio de Janeiro. 2012. 160 f. Dissertação (Mestrado) - Curso de Programa de Pós-graduação em Planejamento Energético, Universidade Federal do Rio de Janeiro, Rio de Janeiro, 2012. Disponível em 〈http://www.ppe.ufrj.br/ppe/production/tesis/nadaud.pdf >. Acesso em 25 de junho de 2018.

ORGANIZATION FOR ECONOMIC CO-OPERATION AND DEVELOPMENT. OECD Core Set of Indicators for Environmental Performance Reviews - a synthesis report by the Group on the State of the Environment - Environmental Monographs. $\quad$ n. $83 . \quad$ Paris. $\quad$ OECD. $1993 \quad 39 \mathrm{p} . \quad$ Disponivel $\quad$ em < http://www.oecd.org/officialdocuments/publicdisplaydocumentpdf/?cote=0CDE/GD(93)179\&docLanguage=En>. Acesso em 25 de junho de 2018.

PROGRAMA DAS NAÇÕES UNIDAS PARA O MEIO AMBIENTE. Oficina Regional para América Latina y el Caribe. Metodologia para la elaboración de los Informes GE0 Ciudades: Manual de Aplicación: Versión 3. Programa de las Naciones Unidas para el Medio Ambiente/Consorcio Parceria 21, 2002. 165p. Disponível em

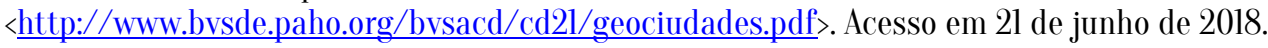

Metodologia para la elaboração de Relatórios GE0 Cidades: Manual de Aplicação. 2. ed. Lomas de Virreyes: Divisão de Avaliação e Alerta Antecipado (DEWA), 2004. 181 p. Disponível em 〈https://edisciplinas.usp.br/pluginfile.php/4218641/_mod_resource/content/1/356_Manual_GE0_Cidades_port.pdf〉 . Acesso em 15 de junho de 2018. 
Projeto Geo Cidades: Relatório Ambiental Urbano Integrado. Informe Geo. Rio de Janeiro: PNUMA/MMA/IBAM/ISER/REDEH. 2002

$2002 . \quad$ Disponível

em

http://www.pnuma.org/deatl/pdf/2002GE0RiodeJaneiro.pdf >. Acesso em 20 de junho de 2018.

PRÜSS-USTIN, A., BOS, R., GORA, F.; BARTRAM, J. 2008. Safer Water, Better Health: Costs, Benefits and Sustainability of Interventions to Protect and Promote Health. World Health Ooganization, Geneva, 2008, 53 p. Disponível em $\langle$ http://www.who.int/quantifying_ehimpacts/publications/saferwater/en/index.html $>$ Acesso em 04 de julho de 2018.

RAHMAN, M. M.; RAHMAN, A. M. Prevalence of acute respiratory tract infections and its risk factors in under five children. Bangladesh Medical Research Council Bulletin, v.78, n.5, p.415-422, Bangladesh,1997.

RAZZOLINI, M. T. P.; GUNTHER, W. M. R. Impactos na saúde das deficiências de acesso a água. Saúde e Sociedade, v. 17, n. $\quad 1, \quad$ p. $\quad 21-32 . \quad$ São $\quad$ Paulo, $2008 . \quad$ Disponível $\quad$ em: http://www.producao.usp.br/bitstream/handle/BDPI/12933/art_RAZZOLINI_Impactos_na_saude_das_deficiencias_ de_acesso_2008.pdf?sequence=1GisAllowed=y $>$. Acesso em 02 de julho de 2018.

RIBEIR0, P. J. M.; BARCELLOS, C.; R0QUE, 0. C. C. Desafios do desenvolvimento em Miracema (RJ): uma abordagem territorial sustentável de saúde e ambiente. Saúde e Sociedade, v. 22, n. 2, p.575-589, São Paulo, 2013. Disponível em http://www.scielo.br/scielo.php?pid=S0104-12902013000200026\&script=sci_abstract\&tlng=pt. Acesso em 20 de junho de 2018.

RI0 DE JANEIR0. Diretoria de Gestão das águas e do Território (DIGAT). Secretaria de Estado do Ambiente. Projeto BIG. Boletim Águas \& Território, Rio de Janeiro, v. 6, p.l-10, 2014. Disponível em 〈http://www.inea.rj.gov.br/cs/groups/public/documents/document/zwew/mdcz/ edisp/inea007374l.pdf〉.

Acesso em 10 de julho de 2018.

Secretaria do Estado do Ambiente (Org.). Zoneamento Ecológico-Econômico Costeiro do Estado do Rio de Janeiro. 3. ed. Rio de Janeiro: Inea, 2014. 5p.

Secretarias de Estado do Ambiente, Secretaria de Estado de Desenvolvimento Regional, Abastecimento e Pesca; Secretaria de Desenvolvimento Econômico, Energia, Indústria e Serviços. Relatório de avaliação da viabilidade ecológica e econômica do Projeto de Ampliação do TAAR/TEBIG. Rio de janeiro, 2012. 46 p.

SANTOS, C. J. et al. Os Desafios e as 0portunidades da Sustentabilidade: um Estudo em uma Empresa do Setor de Engenharia Elétrica Industrial. Revista Metropolitana de Sustentabilidade, v. 5, n. 2, p.75-94, São Paulo, 2015.

SÃo PAUl0 (Município). Secretaria Municipal do Verde e do Meio Ambiente. GE0 Cidade de São Paulo: Panorama do Meio Ambiente Urbano. São Paulo, 2004, $206 \quad$ p. Disponível em < http://www.pnuma.org/deatl/PDF"s/GE0\%20Ciudades/GE0\%20Sa0\%20Paulo-r.pdf >. Acesso em 10 de julho de 2018.

SISINNO, C. L. S. Destino dos resíduos sólidos urbanos e industriais no Estado do Rio de Janeiro: avaliação da toxicidade dos resíduos e suas implicações para o ambiente e para a saúde humana. 2002. 154p. Tese (Doutorado) Escola Nacional de Saúde Pública. Fundação Oswaldo Cruz. Rio de Janeiro, 2002. Disponível em < https://www.arca.fiocruz.br/handle/icict/4374>. Acesso em 11 de julho de 2018.

SNIS - Sistema Nacional de Informações sobre Saneamento. Diagnóstico dos Serviços de Água e Esgotos. Brasília, 2011, 432 p.

Série Histórica: Angra dos Reis. Brasília, 2016. Disponível em 〈http://app3.cidades.gov.br/serieHistorica/ > Acesso em 14 de julho de 2018.

TRIBUNAL DE CONTAS DO ESTADO D0 RI0 DE JANEIR0. Estudos Socioeconômicos dos Municípios do Estado do Rio de Janeiro. 2017. Disponível em: <https://www.tce.rj.gov.br/estudos-socioeconomicosl $>$. Acesso em 10 de julho de 2018.

UNITED NATIONS DEVELOPMENT PROGRAMME. Human development report 2001 - making news techonologies for humam development (Tradução livre). United Nations Development. Programme. p. 9-10, 2001,. New York. 
Avaliação de impactos e danos ambientais em zonas costeiras do Brasil - Angra dos Reis e Paraty

Disponivel em < http://hdr.undp.org/sites/default/files/reports/262/hdr_2001_en.pdf $>$. Acesso em 12 de julho de 2018.

UNIVERSIDADE D0 ESTAD0 D0 RI0 DE JANEIR0 (Paraty). Plano Municipal de Saneamento Básico da Prefeitura Municipal de Paraty: Resíduos Sólidos Urbanos. Paraty. 2011. 35 p. Disponível em <www.paraty.rj.gov.br/camaraparaty/painel/paginas.../anexo_6_05042016104951.pdf >. Acesso em 22 de junho de 2018.

VARGAS, H. C. População e Meio Ambiente na Entrada do terceiro Milênio: em Busca de uma Nova Ética. In: Encontro Nacional de Estudos Populacionais. População, globalização e exclusão. 1998. Caxambu. ABEP. Anais. Caxambu, 1998. p. $1-22$ Disponível em http://fau.usp.br/depprojeto/labcom/produtos/1998_vargas_populameioambiente.pdf`. Acesso em 12 de julho de 2018.

VASCONCELOS, A. C. F. et al. Pressão Estado Impacto Resposta: um estudo em curtumes artesanais na Paraíba. In: Encontro Internacional sobre Gestão e Meio Ambiente, 2014, Paraíba. Anais, p. 1-15, Paraíba, 2014. Disponível em < http://www.engema.org.br/XVIENGEMA/412.pdf $>$. Acesso em 20 de maio de 2018.

VICTORA, C. G. Factores de Riesgo em las Infecciones Respiratorias Agudas Bajas. In: BENGUIGUI, Y. et al. Infecciones Respiratorias en Ñinos, p. 45-63. Washington DC: Pan American Health Organization. 1996. 